\title{
Cell-Phone Recycling by Solvolysis for Recovery of Metals
}

\author{
Lorena Eugenia Sánchez Cadena1, Zeferino Gamiño Arroyo², \\ Mario Alberto González Lara², Q. Demetrio Quiroz ${ }^{1}$ \\ ${ }^{1}$ Departamento de Ingeniería Civil, Universidad de Guanajuato, DI, Av. Juárez 77, CP 36000, Guanajuato, Gto., \\ México \\ ${ }^{2}$ Departamento de Ingeniería Química, Universidad de Guanajuato, DCNyE, Noria Alta s/n, CP 36050, \\ Guanajuato, Gto., México \\ Email: hau10@hotmail.com, hau10@hotmail.com
}

Received December 2014

\section{Abstract}

Mobile phones represent a significant and growing problem with respect to electrical waste and electronic equipment (WEEE). Nevertheless, they are perhaps one of the most valuable electronic products, since they are an important resource for the recovery of metals in terms of mass and volume. In this research a chemical recycling of mobile phones by solvolysis was investigated. The processing was performed by comminution in a hammer mill followed by screening to obtain mesh-4 sized flakes. Flakes were subjected to solvolysis. Different reaction conditions were tested. A reaction time between $2-7$ hours and a temperature between $150^{\circ} \mathrm{C}-300^{\circ} \mathrm{C}$ were the optimum conditions to dissolve the polymer contained in mobile phones. Metals were separated by filtration. Chemical analyses (ATR FT-IR, UV) were carried out on the solvent and the mobile phone flakes before and after solvolysis. A SEM study was carried out, before and after solvolysis, but only to the mobile phone flakes. Thermal transitions of mobile phone flakes were determined by DSC. Chemical results showed that some aromatic species migrate from mobile phones flakes to the solvent, due to the solvolysis reaction. Thermal analysis showed that the $\mathrm{Tg}$, (glass transition temperature) of mobile phone flakes after solvolysis was different to $\mathrm{Tg}$ of the polymer before solvolysis, this is due to chemical changes in the molecule. A comparative SEM study revealed that, after solvolysis, the polymer contained in mobile phone flakes is more elastomeric. After solvolysis, solvent was recovered by means of a rotatory evaporator, so that it can be used again. The results obtained in this research showed that solvolysis is an alternative for metal recovery from mobile phones.

\section{Keywords}

Cell-Phones, Solvolysis, Recycling

\section{Introduction}

Over the last few decades, the polymer industry has been very important, specifically in the field of electronics and 
communication, such as in cellular phones. At the beginning of the 2000's, there were 500 million cell phone users, in 2011 this number had increased to 5750 million world-wide. Generally, cell phones are not recycled in Mexico [1]. This provokes the generation of waste that should not be thrown away with domestic trash, as they are composite materials that contain conducting liquids and metals in the battery that cause soil and water pollution by lixiviation and air pollution when combusted. The above in addition to the fact that its degradation is very slow.

Over time, physical and structural changes in cell phones have been notable. The preference for the latter in this technology is part of modern youth psychology. This contributes to the considerable and growing number of cell phones in disuse. The presence of metals in cell phones creates the expectation of being able to obtain them in solid form, in order to do so, the polymer section should be removed [2]. Different kinds of recycling may be applied (physical, chemical, and incineration) [3]. However, the physical method cannot separate the two components (change in crystalline structure; metallic solutions). We therefore favor chemical recycling, a catalytic solvolysis reaction. Glycols are good solvents due to its hydrogen bridges that can establish, between one molecule and another.

Method Different reactions were carried out where variables were tested such as; temperature $\left(150^{\circ} \mathrm{C}-220^{\circ} \mathrm{C}\right)$, solvent quantity (glycol), reaction time, catalyst quantity, and agitation.

\section{Method}

1) Collected cell phones were opened to remove the batteries and metal plates.

2) The cell phones were then pulverized and sieved.

3) The system was set-up, at a small or large scale, correctly sealing to prevent leaks.

4) The initial quantity of pulverized cell phone was measured.

5) Glicol was added until the level achieved was slightly higher than the cell phone powder.

6) A nitrogen atmosphere was applied.

7) The solvent is separated from the metals.

8) The solvolysis liquid, which is the solvent, is recovered in a rotary evaporator.

9) Different instrumental analyses are applied; FT-IR ATR, UV-Vis, DSC and SEM, with the sample liquids and solids, before and after the solvolysis.

\section{Results and Discussions}

\subsection{FT-IR ATR Analysis}

A comparative study was carried out between the FT-IR ATR spectra of the polymer before and after treatment with the solvent.

This study shows how aromatic species with a C-H bond that are found outside the plane on $\left(751 \mathrm{~cm}^{-1}\right)$ present on the black cell phone before the solvolysis, migrate towards the solvent $\left(758 \mathrm{~cm}^{-1}\right)$ (Figure 1 and Figure 2).

Additionally, the signal of $1586 \mathrm{~cm}^{-1}$ related to aromatics di and tri substitutes appear in the solvent (polymer + glycol), it is clear that this signal comes from the polymer as the solvent is not aromatic.

The peak at $1066 \mathrm{~cm}^{-1}$ present on the column of the black cell phone without treatment indicates the presence of phenols, said signal appears again in the solvent, further, between $1241-1267 \mathrm{~cm}^{-1}$, the presence of aromatic ethers are noted, in the untreated black cell phone and in the solvent we can see similar signs.

The observed peak at $1720 \mathrm{~cm}^{-1}$ associated to a carboxyl group, present in the untreated black cell phone disappeared in the solvent spectra [4].

According to the above, we can assert that the black cell phone polymer has been chemically attacked, as certain chemical species pass to the solution.

\subsection{UV Analysis}

A study of the UV spectrum was carried out using ethanol to dilute the previously filtered solvent, results are shown in Figure 3. As may be observed, a signal in the 200 to $300 \mathrm{~nm}$ range is detected, indicating the presence of phenol aromatic compounds [5]. These are the products of secondary reactions from the dissolution process.

\subsection{SEM Study}

A study in a scanning electron microscope was carried out, coupled with X-ray dispersion equipment for element 


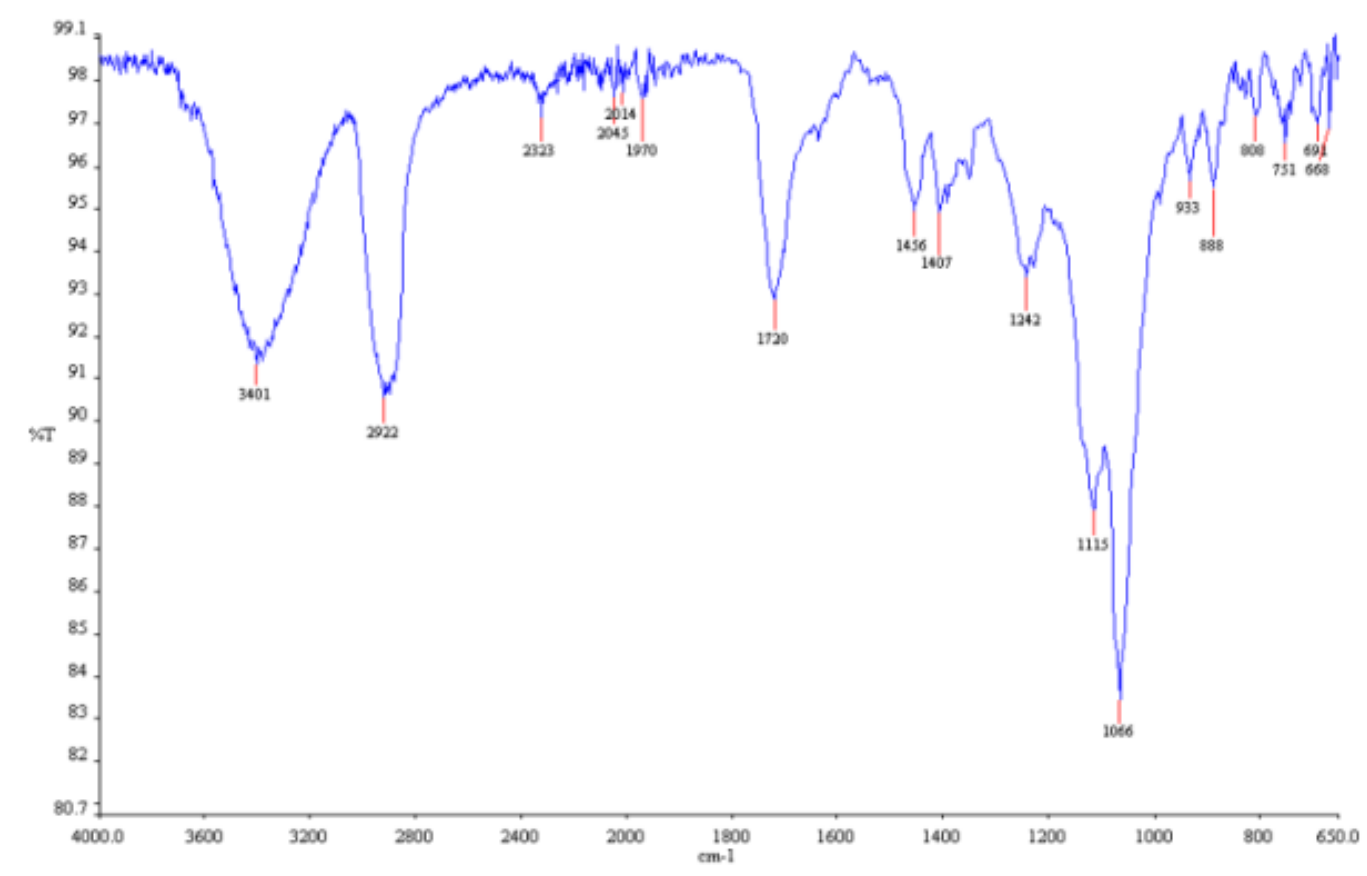

Figure 1. ATR spectra of the cell phone before treatment.

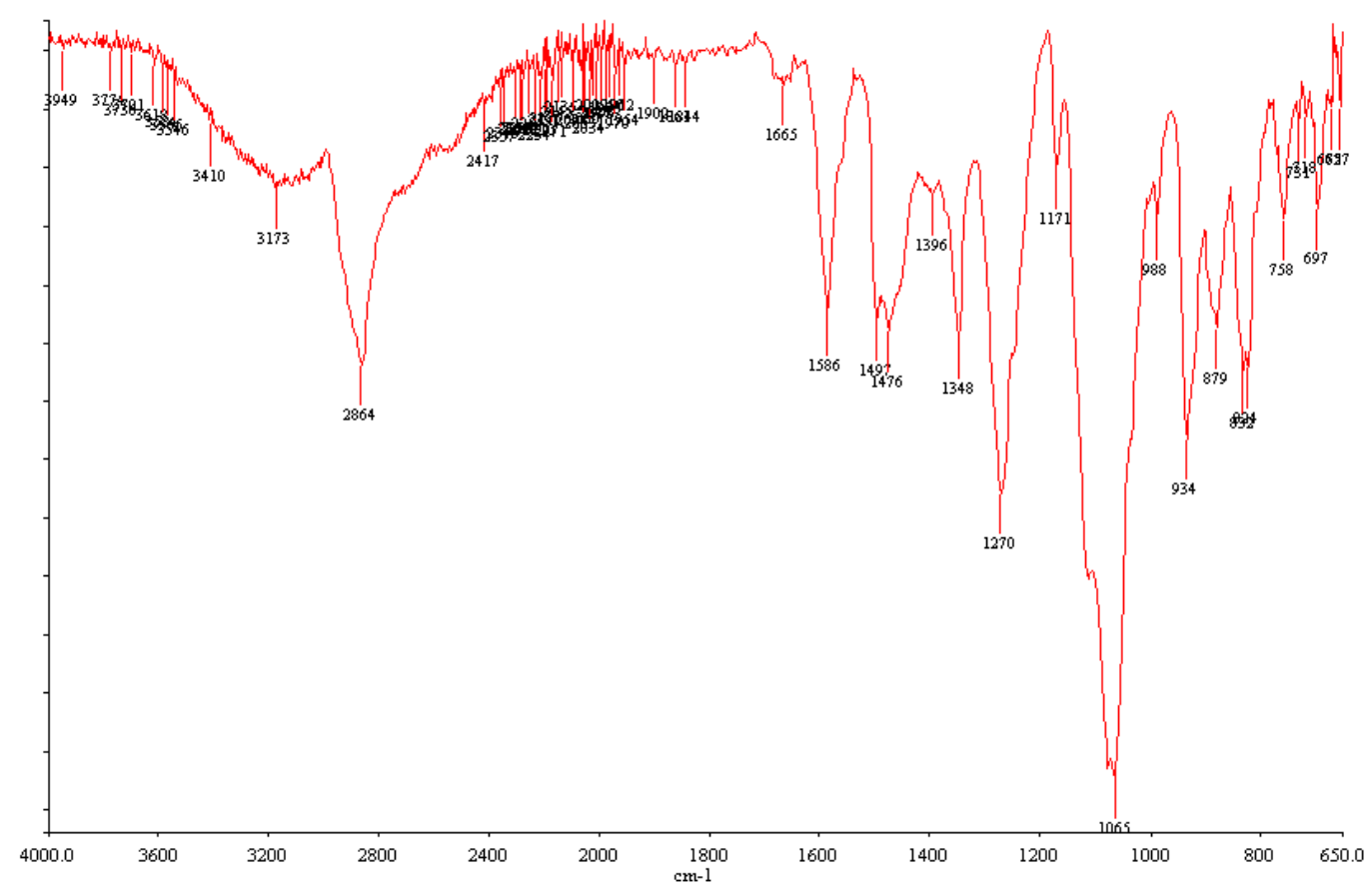

Figure 2. FT-IR ATR spectrum of the solvent after treatment.

analysis. The results are shown in Figure 4. As can be seen, in the photo on the left, the polymer before the treatment is more rigid and after the treatment becomes more elastic, such as the photo on the right. It is normal to break macromolecules, some small molecular species have greater movement.

The increased pore size provokes the detachment of micro-particles, favoring migration towards the glycol. The SEM analysis with the coupled X-ray dispersion equipment, allowed us to know the elements present in the sample which are: $\mathrm{Si}, \mathrm{Pb}, \mathrm{C}$, and $\mathrm{Al}$. The presence of metals is associated with small metal filaments that are left behind. 


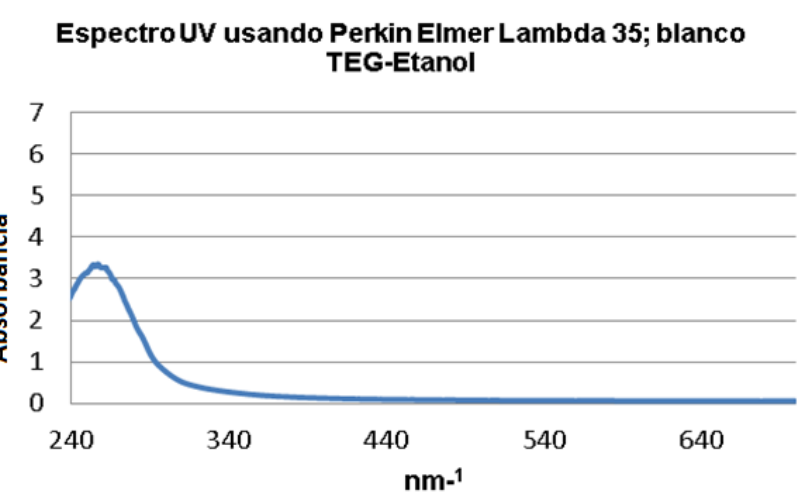

Figure 3. UV spectrum of the solvent that remains after treatment.
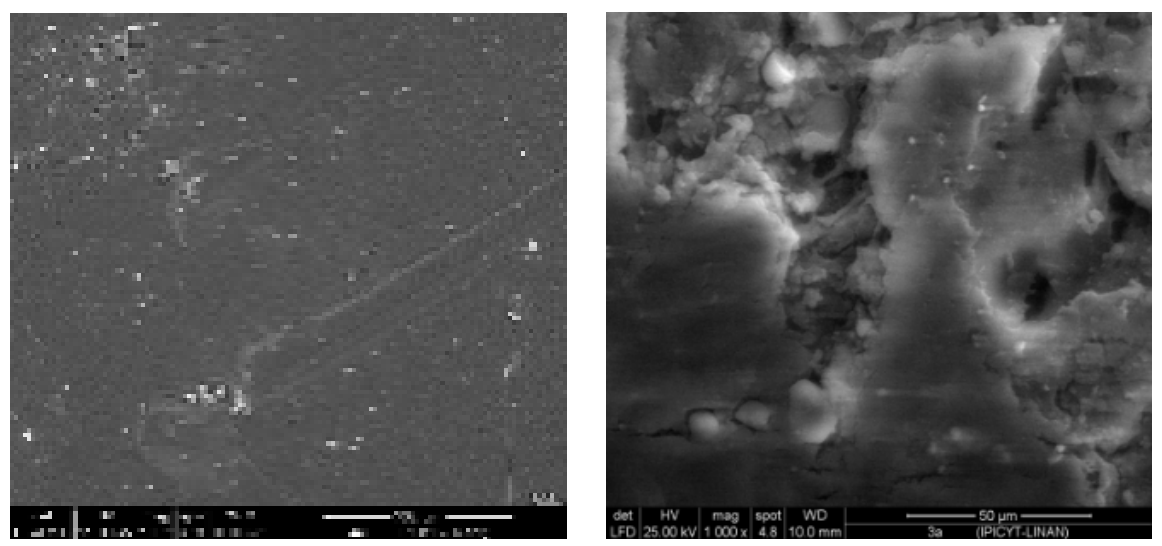

Figure 4. Cell photo before and after treatment.

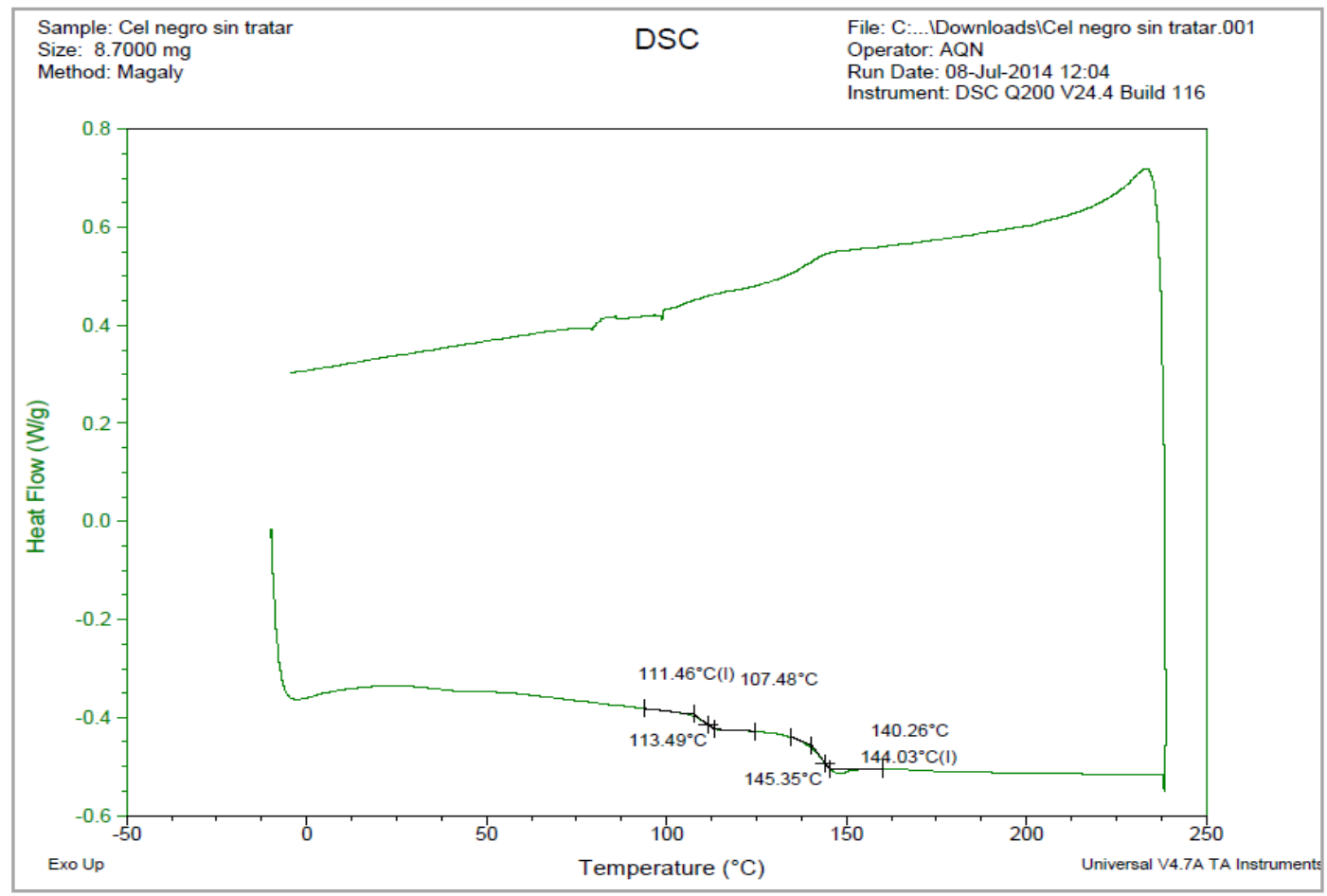

Figure 5. Untreated DSC sample. 


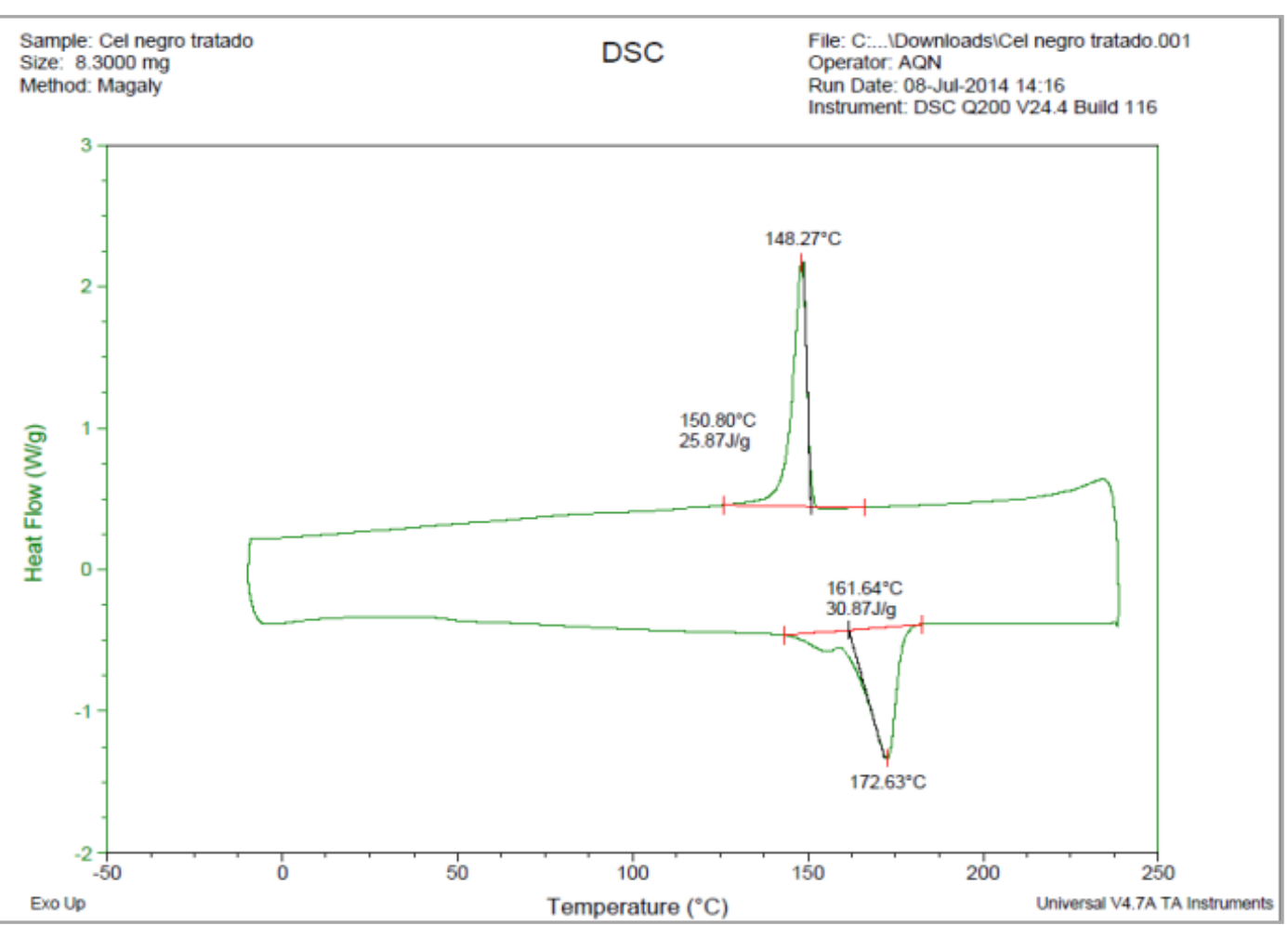

Figure 6. Treated DSC sample.

\subsection{DSC Analysis}

The differential sweeping calorimetry analysis on polymer samples of black cell phones, one before treatment, and one after treatment. The thermograms obtained are shown in Figure 5 and Figure 6.

The comparative study shows that the glass transition temperature in each sample is different. During the warming of the sample without treatment two temperatures were observed, $17.48^{\circ} \mathrm{C}$ and $144.03^{\circ} \mathrm{C}$, however, in the treated polymer only one temperature is observed: $161.64^{\circ} \mathrm{C}$. In the case of cooling in the treated sample, no change was detected from $148.27^{\circ} \mathrm{C}$.

The aforementioned results proves that the chemical organization of the material has been modified, changing the structure of the mixed solid (amorphous and crystalline, completely modifying the mechanical properties of the material [6].

\section{Conclusions}

This study allows us to conclude that cell phone recycling by solvolysis of the polymer part to recuperate metals is possible, showing how well glycol works as a solvent, and a reaction of $150^{\circ} \mathrm{C}$ to $220^{\circ} \mathrm{C}$, with agitation and with a basic catalyst, and reaction times varying from 1 to 7 hours.

Through spectrophotometric evidence of the presence of multiple compounds present in the solvent from the polymer, it has been verified that the macromolecule has been chemically altered. More generally, the instrumental analysis (FT-IR ATR, UV, DSC and SEM) show that de-polymerization has taken place.

The majority of solids left after the reaction are metals, but there are still some polymer particles, and we therefore suggest prolonging the reaction time. These solids are more resistant to solvolysis, due to the fact that they are linear saturated polymers or contain tertiary carbons. The presence of a basic atmosphere increases the depolymerization. The absence of oxygen prevents hydroperoxides from forming (these compounds are easily decomposed to give macro-radicals).

\section{Acknowledgements}

DAIP, University of Guanajuato, and IPICYP. 


\section{References}

[1] www.milenio.com/negocios/mexico-reciclan-mil-celulares-mes

[2] Vinh, H.H. (2010) Thiosulfate Leaching of Gold from Waste Mobile Phones. Journal of Hazardous Materials, 178, 1115-1119.

[3] Sheirs, J. (1998) Polymer Recycling Science Technology and Applications. John Wiley and Sons, 381-406.

[4] Koening, L. (1992) Spectroscopy of Polymers. ACS Professional Reference Book, USA.

[5] Silverstein, Basler, Morrill (1998) Identification Spectroscopique de composes organiques; de boeck.

[6] Sanchez Cadena, L.E., Alvarado Tenorio, B., Romo Uribe, A., Campillo, B., Flores, O. and Huifen, Y. (2013) HotPressed Boards Based on Recycled High-Density Polyethylene Tetrapack: Mechanical Properties and Fracture Behavior. Reinforced Plastics and Composites. 